\title{
Functional Anatomy of the Choroidal Circulation: Methyl Methacrylate Casting of Human Choroid
}

\author{
J. M. OLVER \\ London
}

\begin{abstract}
Summary
The functional anatomy of the normal choroidal circulation in man is described from scanning electron microscopic examination of methyl methacrylate microvascular casts. Distal and para-optic short posterior ciliary arteries supply wedge-shaped areas of choroid. Regional variations in choriocapillary morphology are well recognised; the lobules are densely packed at the posterior pole with a high capillary to inter-capillary ratio. Choroidal capillaries are flattened providing a large surface area for metabolic exchange with the retinal pigment epithelium. In acute choroidal ischaemia (from a variety of systemic disease), wedge shaped choroidal lesions may correspond to occlusion of short posterior ciliary arteries and geographic or focal lesions to occlusion of choroidal arterioles or choriocapillary lobules.
\end{abstract}

Several techniques have been employed to define the anatomy of the choroidal circulation and its supply in man, including dissection, ${ }^{1-3}$ histology, ${ }^{4}$ indian ink injections, ${ }^{5}$ flat preparations, ${ }^{6-9}$ and neoprene latex casts. ${ }^{5,10-13}$ From examination of earlier casts using neoprene latex ${ }^{11},{ }^{12}$ the choroid was regarded as highly anastomotic with little potential for ischaemia occurring. This was contrary to both early and more recent interpretation of findings based on clinical ${ }^{14-26}$ and experimental $^{27-35}$ evidence. Techniques including clearing ${ }^{36}$ Roentgen ray imaging ${ }^{37}$ and methylmethacrylate vascular casting ${ }^{38-41}$ have since added to our understanding of the functional anatomy of the choroid. The purpose of this paper is to elaborate on the arrangement of the vasculature and identify its relevance to acute choroidal ischaemia.

\section{Methods}

The anatomy of the choroidal circulation was examined from methyl methacrylate microvascular casts prepared according to standard methods. ${ }^{42}$ The entire orbital contents and intracavernous part of the internal carotid artery were exenterated at autopsy $36-48$ hours post mortem (preserving the lids in situ). The ophthalmic artery was canulated. Primary infusion of phosphate buffered saline (PBS) was followed by gluteraldehyde $0.5 \%$ in PBS, at infusion pressures of $120-175$ $\mathrm{mmHg}$ at physiological temperatures. Casting was achieved by secondary perfusation with 25-50 mls thinned methyl methacrylate resin (using a base of Batson's no.17, Polysciences) injected under manometric control until the resin hardened (7-10 minutes). The surrounding tissue was corroded in six Molar potassium hydroxide which was changed regularly and the casts washed in distilled water and air dried. The casts were gold sputter coated $(50 \mathrm{~nm})$ and dissected appropriately to include examination of the choroid. Ocular casts were examined by the scanning electron microscope (Hitachi S-520, Tokyo, Japan) either whole or as dissected fragments mounted on an aluminium stub, at $20 \mathrm{kv}$ and magnifications of $\times 22$ to $\times 1.3 \mathrm{k}$.

\section{Results}

The main findings are illustrated in Figure 


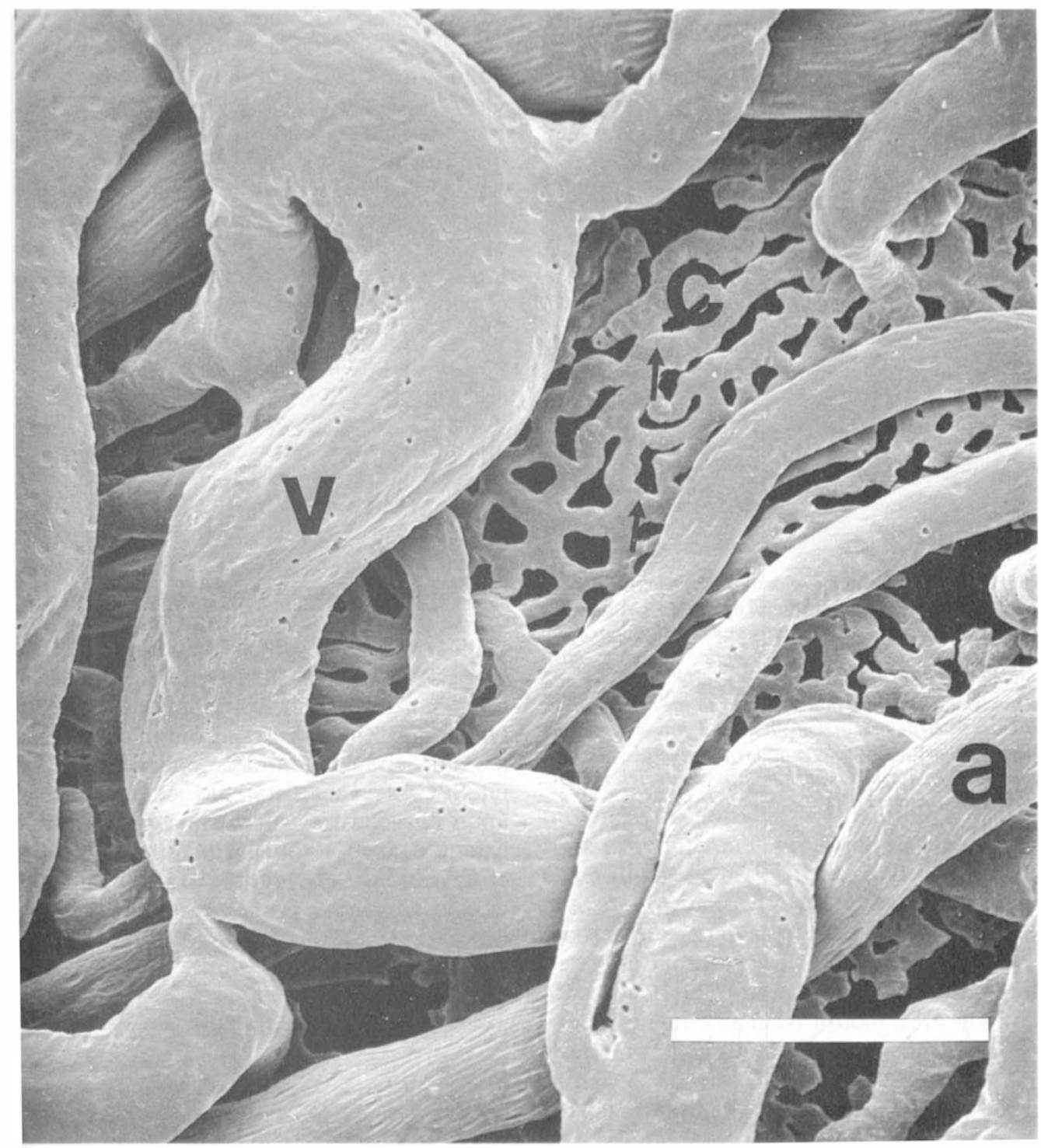

Fig. 1. Scanning electron photomicrograph of cast of choroidal vasculature viewed from the sclerad side showing venules (v) (with oval endothelial nuclear impressions) draining choriocapillary lobules, arterioles (a) (with elongated endothelial nuclear impressions) and choriocapillaris (c) (with small oval endothelial nuclear impressions, arrows). Bar $=231 \mu \mathrm{m}$.

1-5, based on compilations from 21 ocular vacular casts. Arteries and veins were differentiated by the appearance of the endothelial nuclear impressions on the surface of the intra-lumenal vascular casts (Fig. 1). Endothelial nuclear impressions were noted on the outer surface of the choriocapillaries cast (sclerad surface) but not the inner surface (retinal aspect) towards the retinal pigment epithelium.

The short posterior ciliary arteries (SPCAs) were formed by second and third order divisions of the posterior ciliary arteries (PCAs) originating from the ophthalmic artery. The SPCAs were grouped usually in two bundles (temporal and medial) close to the posterior 


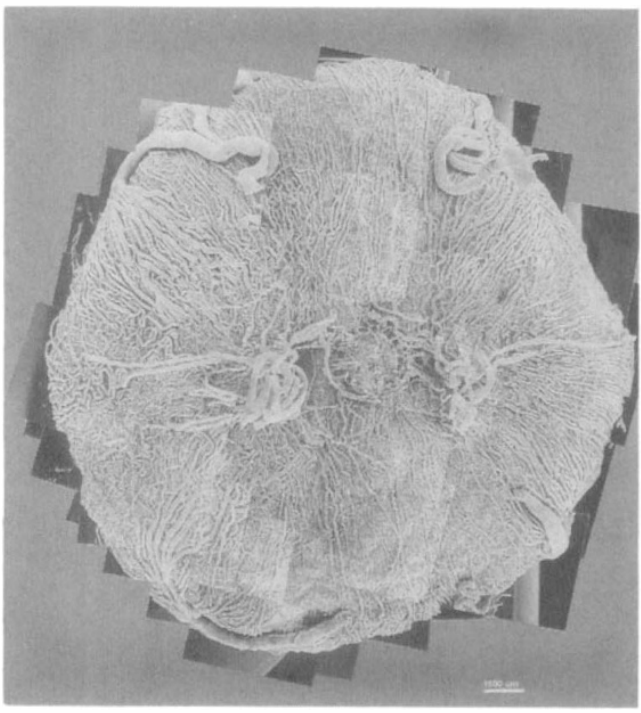

Fig. 2a. Photomontage of cast of the posterior pole of a left eye showing temporal and medial SPCA bundles supplying choroidal vasculature and retrolaminar optic nerve vasculature. The para-optic branches have divided on each side to form the 'circle' of Haller and Zinn which provides pial branches to the retrolaminar optic nerve and recurrent choroidal branches to the peri-papillary choroid and peripheral vertical meridional choroid. The lateral and medial LPCAs have been truncated at the equator. Vortex veins are clearly seen.

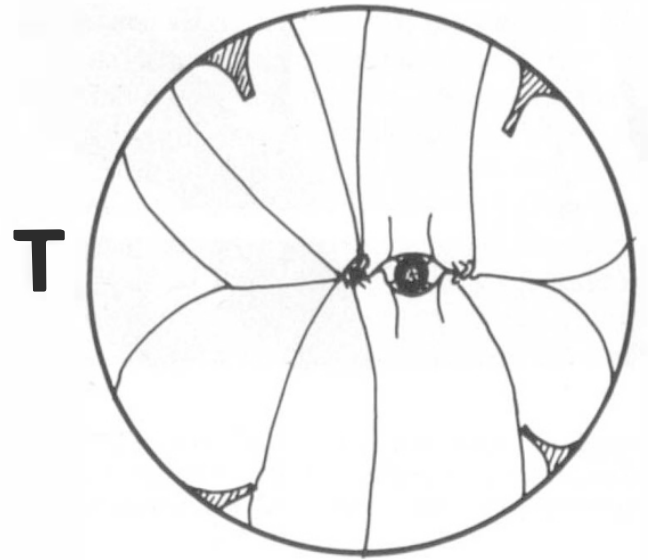

Fig. 2b. Diagrammatic representation of above montage of left eye showing gross division of the choroid into triangular and trapezoid areas supplied by the SPCAs. T=temporal.

aspect of the globe at a short distance from the optic nerve (Fig. 2).

The distance from the edge of the posterior scleral foramen to the temporal bundle was greater than to the nasal bundle. Within each bundle the SPCAs sub-divided further into distal branches and a smaller para-optic branch. This division occurred more posteriorly (further away from globe) in the temporal bundle than in the nasal bundle and therefore was more readily identifiable in the temporal bundle. The more numerous and larger distal SPCAs supplied triangular areas of choroid temporally and nasally. The distal SPCAs entered the sclera at right angles close to their bundle of origin before radiating towards the periphery. The triangular shaped areas of choroid supplied by the distal SPCAs are illustrated in Figure 2. The apices of the triangular areas were posterior close to the point of entry of each SPCA from the temporal and nasal bundles. The smaller and less numerous para-optic SPCAs supplied the vertical and peripapillary choroid, either directly or via branches derived from the 'Circle' of Haller and Zinn which they formed. The shape of the area of choroid supplied by recurrent choroidal branches from the circle of Haller and Zinn was trapezoid in contrast to the more triangular areas supplied by the distal SPCAs. The distal SPCAs encroached upon the vertical meridian to a variable extent. Branches from the undersurface of the SPCAs in the outer choroidal layer (Haller's

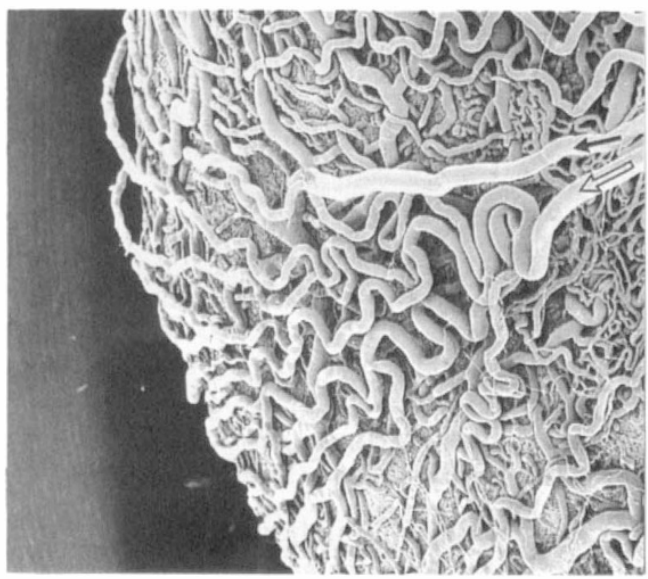

Fig. 2c. Detail from temporal part of montage showing recurrent choroidal branch (empty arrow) of lateral LPCA radiating out to supply a triangular shaped area of choroid. Lateral LPCA (black arrow) continues around the globe but has been truncated in this specimen. Note dense vasculature at macular on right. 


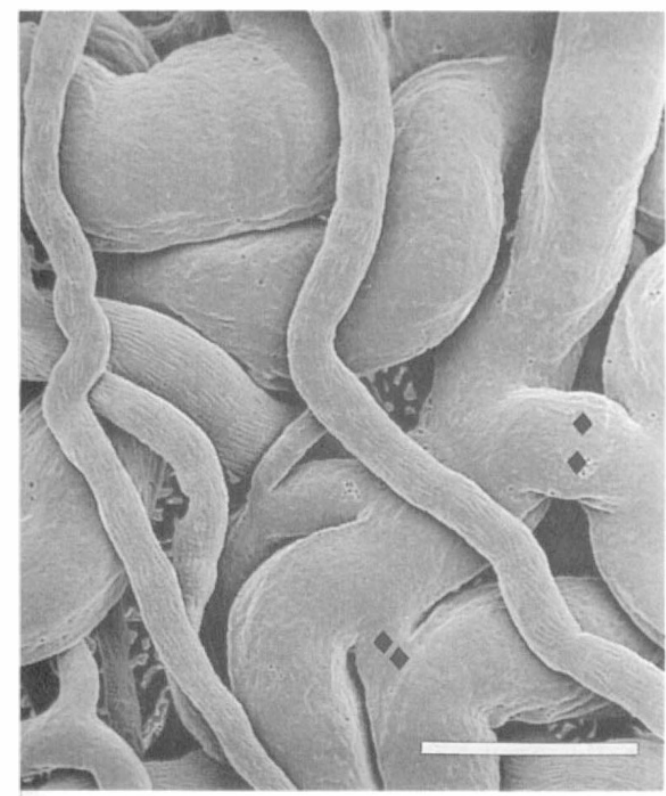

Fig. 3. Dense choroidal vasculature at posterior pole close to fovea. Inter-venous anastomoses demonstrated (black diamonds). Sclerad surface of choriocapillaris just visible. Bar $=270 \mu \mathrm{m}$.

layer) gave rise to choroidal arterioles in the intermediate layer (Sattler's layer).

The long posterior ciliary arteries (LPCAs) arose directly from distal SPCAs. The distal SPCA forming the lateral LPCA consistently supplied a recurrent branch towards the posterior pole whereas the medial LPCA continued directly around the globe, without a branch to the posterior pole. Recurrent choroidal arteries from the anterior segment (branches of the LPCAs, of intra-muscular arteries and from vertical anterior ciliary arteries) contributed to the supply of the anterior choroid. Inter-capillary and interarteriolar anastomoses were noted rarely, predominantly in the vertical meridian, between the anterior and posterior uvea. Small inter-arteriolar anastomoses and intervenular anastomoses were encountered at the posterior pole (Fig. 3) but not arteriolar-venular anastomoses.

Terminal choroidal arterioles supplied the choriocapillaris. At the posterior pole the lobular appearance of the choroid was only readily apparent on closer inspection (Fig. 4a); lobules were small, densely packed and several small choroidal arterioles could supply a single lobule entering at right angles to the plane of the choriocapillaris. The lobular pattern of the choriocapillaris became more evident towards the equator (Fig. 4b) and periphery (Fig. 4c) where the lobules were progressively larger, radially elongated and with arteriolar and venular components found in the same plane as the choriocapillaris. In addition, the diameters of the capillary casts increased towards the periphery, with corresponding wider and progressively more elongated intercapillary spaces (see Table I). The choroidal capillaries were flattened anteroposteriorly having an elliptical cross section (Figs. 5a, b) and although the diameters of choroidal capillary lumens varied, their antero-posterior thickness remained between 8-20 $\mu \mathrm{m}$.

\section{Discussion}

\section{Present Clinical Concepts}

The extent to which the choroidal circulation is segmentally supplied ${ }^{2,8,9,14,15,27,34}$ or richly anastomotic ${ }^{4,11,12,28}$ has been the subject of much debate. Our main understanding of the functional anatomy of the choroid has come from examination of patients with acute disturbances of choroidal vasculature $e^{14,15,19-26}$ and from experimentally produced ischaemia. ${ }^{29-35}$ Clinically two types of acute choroidal ischaemia are recognised with systemic disease: (i) triangular-shaped areas of choroidal filling delay on fluorescein angiography with variable overlying retinal dysfunction, and (ii) geographic or focal lesions with marked overlying retinal and pigment epithelial disturbance. The first is attributed to complete or partial occlusion of PCAs or SPCAs from systemic diseases such as temporal arteritis. The second is attributed to occlusion of choroidal arterioles or choriocapillary lobules in, for instance, toxaemia of pregnancy or DIC. (See aetiologies, Table II). Both forms usually resolve spontaneously or may leave characteristic lesions (triangular shaped scars or small Elschnig spots). The tendency for rapid spontaneous resolution over several days implies that although the choroidal circulation functionally has a segmental supply, it is not truly endarterial. The potential for resolution of ischaemia is supported by modern vascular casting and experimental fluores- 


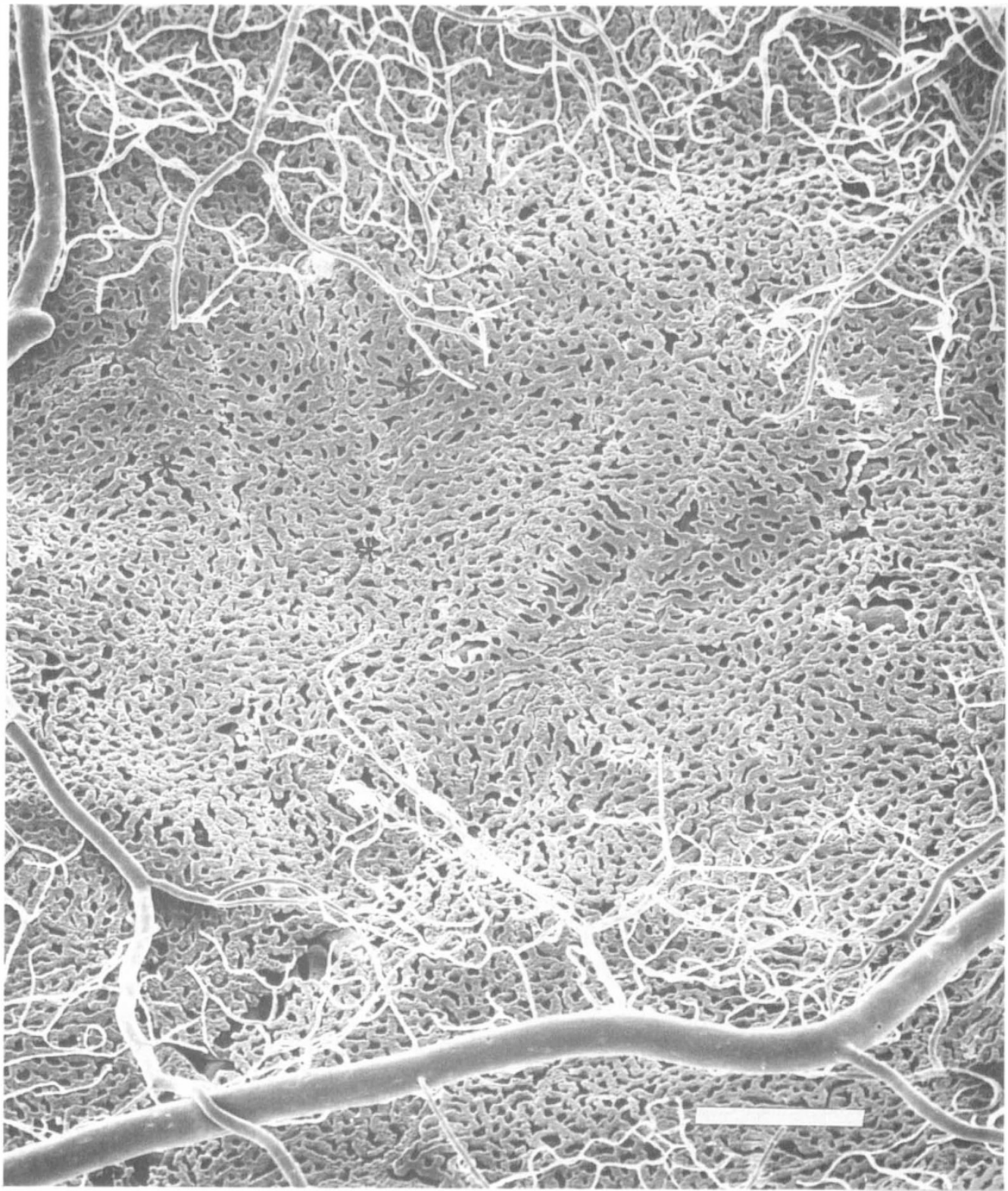

Fig. 4a. Posterior pole choriocapillaris viewed from retinal aspect. Remnants of the inferior retinal vessel arcade and retinal capillaries are visible. Lobular appearance is difficult to distinguish but can be identified. ${ }^{*}=$ choroidal arteriole opening. Bar $=250 \mu \mathrm{m}$. 


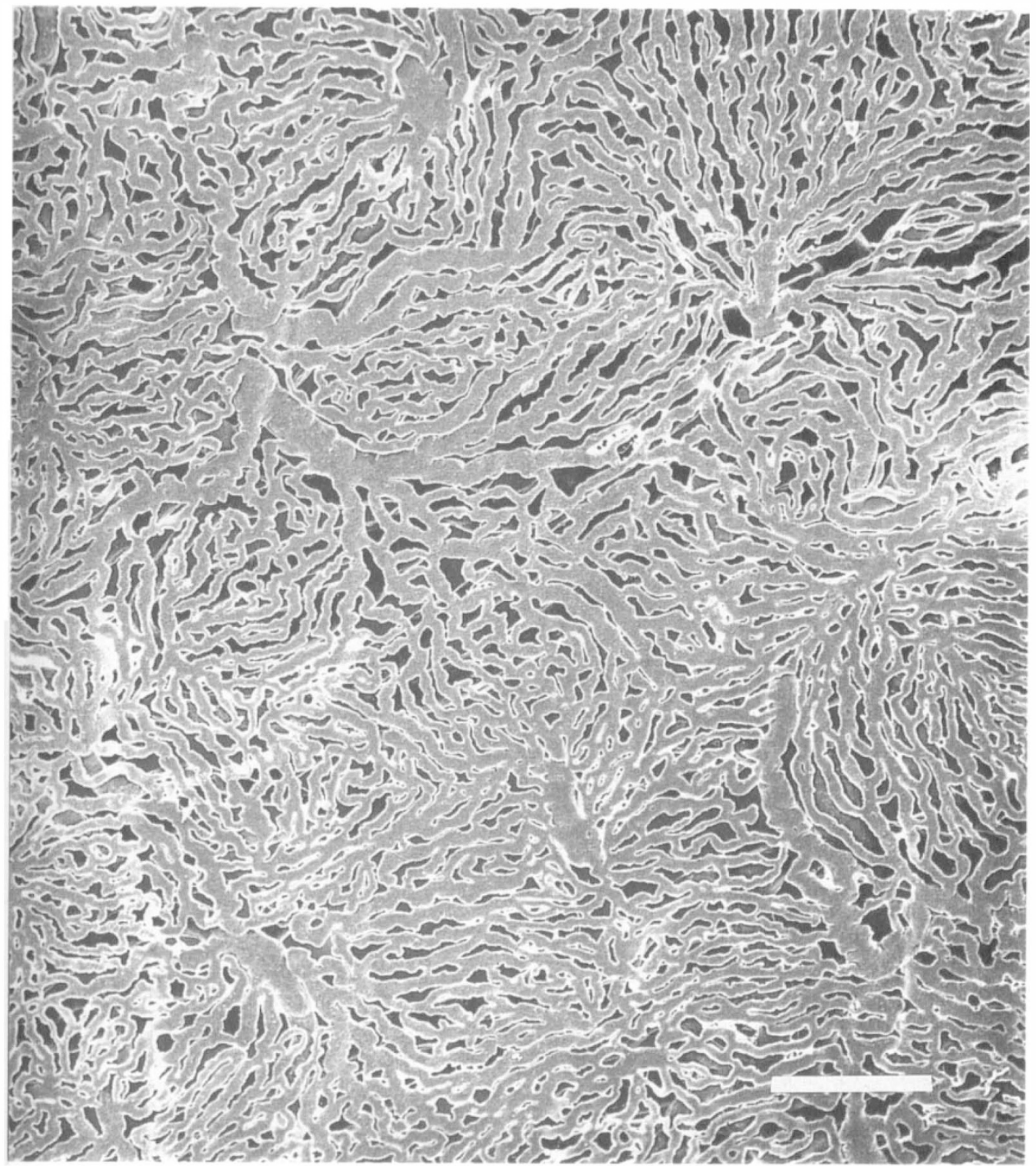

Fig. 4b. Equatorial choriocapillaris viewed from retinal aspect. Lobular pattern is more apparent. Terminal parts of arterioles and venules are visible. Bar $=250 \mu \mathrm{m}$. 


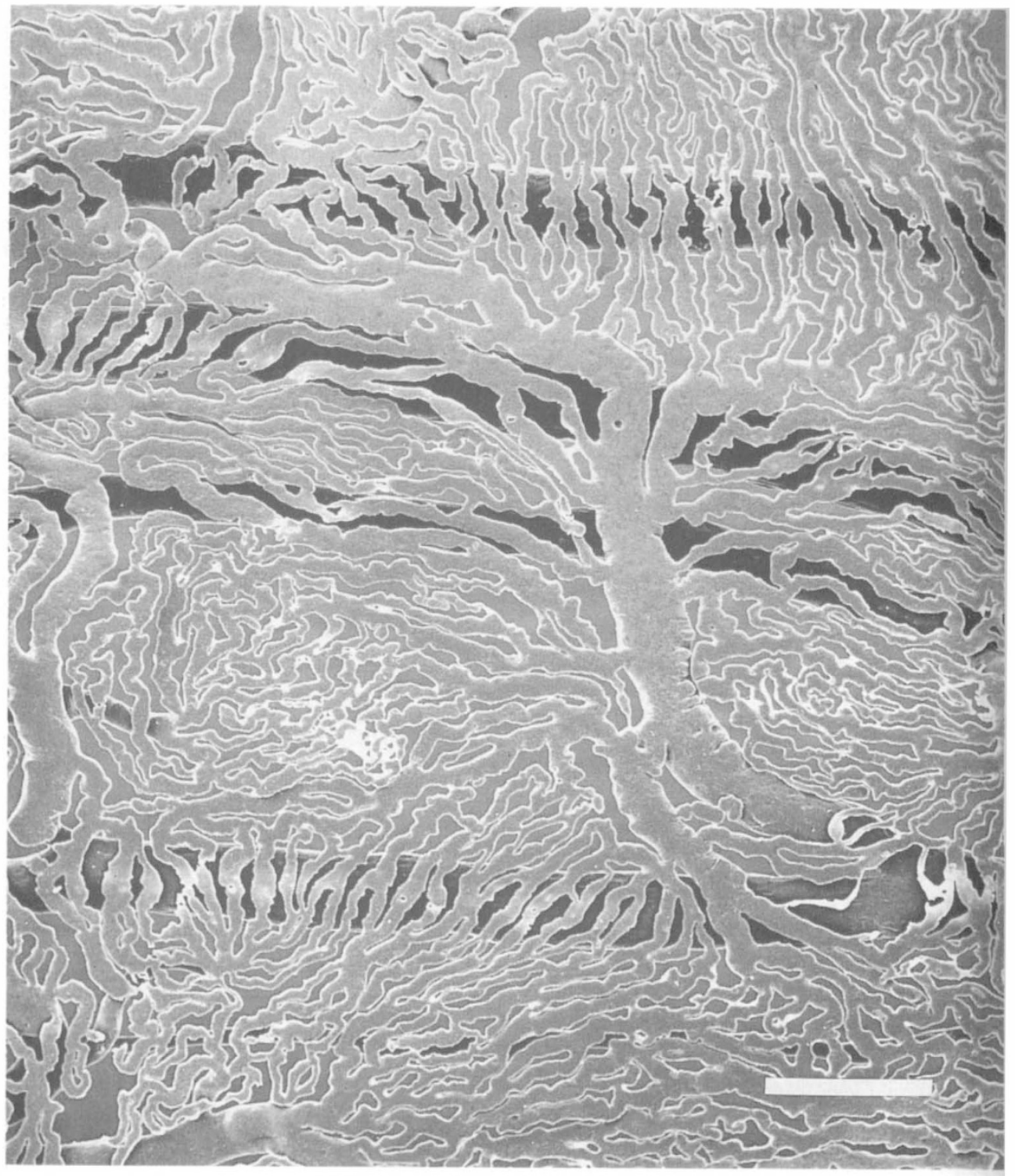

Fig. 4c. Peripheral choriocapillaris viewed from retinal aspect. Evident large fan-shaped lobules. Arterioles and venules lie in the same plane as the capillaries. Bar $=250 \mu \mathrm{m}$. 


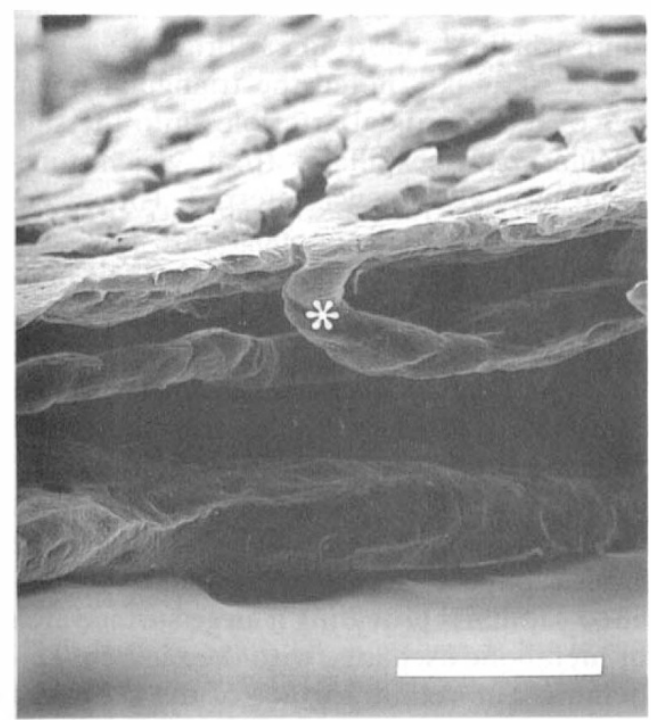

Fig. 5a. Cross section of equatorial choroid showing flattened wide diametered capillaries and a draining venule (star). Bar $=60 \mu \mathrm{m}$.

cein angiographic studies. Yoneya and $\mathrm{Tso}^{40}$ demonstrated arterial-arterial anastomoses in the posterior choroid from methyl methacrylate vascular casts of human eyes, as had Ring and Fujino, ${ }^{13}$ Weiter and Ernest ${ }^{5}$ from neoprene latex casts. Similarly, in experimentally induced large vessel disease fluorescein angiographic resolution is often rapid..$^{30,31,43,44}$ The potential for ischaemia was first demonstrated from early experimental SPCA division ${ }^{27}$ and clinical observations of large triangular cicatricial choroidal lesions in association with systemic disease. $.^{14},{ }^{15}$ It was suggested from these early studies that the SPCAs supplied the choroid segmentally, although Nicholls ${ }^{28}$ found experimentally that sufficient numbers of SPCAs had to be divided to produce evident ischaemia. More recent experimental evidence from injection of microspheres ${ }^{32,35}$ and division of PCAs and SPCAs $s^{30,31,33-35}$ also supported the concept that the choroid was supplied segmentally. The potential for acute

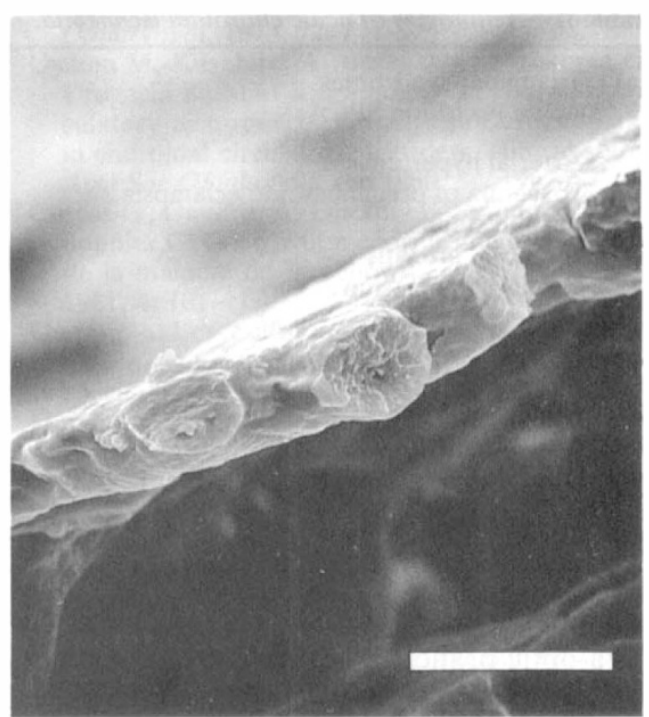

Fig. 5b. High magnification of cross section of choriocapillaris at posterior pole. Bar $=23.1 \mu \mathrm{m}$.

choroidal ischaemia exists in man contrary to conclusions based on neoprene latex casting $^{11,12}$ and limited experimental ${ }^{28}$ and histological $^{4}$ evidence.

\section{Vascular Anatomy}

Although the main morphological features of the choroidal circulation are well known, our knowledge is incomplete. Rigid methyl methacrylate microvascular casting has provided several advantages over other techniques of morphological examination. It allows three dimensional examination of the choroid with sequential micro-dissection and accurate identification of arteries and veins. Better quality polymers with lower viscosities have largely overcome problems of fragility and poor capillary filling. ${ }^{45,46}$ Vascular casting, however does not provide dynamic and physiological information on the function of the choroid, but can be interpreted in the light of clinical and experimental data.

Table I Choriocapillary regional variations. Dimensions $\mu \mathrm{m}$.

\begin{tabular}{lccc}
\hline & Lobule size & Capillary diameter & Intercapillary distance \\
\hline Posterior pole & $200-350$ & $16-20$ & $5-20$ \\
Equator & $300-400$ & $20-50$ & $20-200$ \\
Periphery & $500-1000$ & $20+$ & $20-300$ \\
\hline
\end{tabular}


Table II Aetiologies of acute choroidal ischaemia.

(a) Triangular syndromes

Acute occlusion SPCAs

Arterial hypertension

Toxaemia of pregnancy and eclampsia

Carotid stenosis

Temporal arteritis

Ocular compression

(b) Focal or geographic

Multiple arteriolar/capillary occlusion

Accelerated hypertension

AMPPE

DIC

ITP

Eosinophilia

The division of the SPCAs into distal and para-optic branches is an important morphological feature in the supply of the choroidal vasculature. From neoprene casts, Weiter and Ernest ${ }^{5}$ first described the temporal short posterior ciliary arteries sub-dividing into a submacular group and a separate unnamed group closer to the optic nerve. The sub-macular group was so named because of its site of entry but the supply was not solely sub-macular. The sub-division of the SPCAs into constant distal and para-optic branches was later confirmed by Ducournou ${ }^{37}$ and provides the key to understanding the sectoral supply of the SPCAs and the altitudinal supply of the retrolaminar optic nerve. ${ }^{47}$

The small para-optic branches are significant in forming the circle of Haller and Zinn, an intrascleral anastomosis in man between temporal and nasal paraoptic branches having superior and inferior parts. Pial and recurrent choroidal branches originate from this anastomosis and supply the retro-laminar optic nerve and the peripapillary and vertical meridional choroid.

The triangular nature of acute choroidal ischaemia is well recorded and corresponds to the triangular areas supplied by the distal SPCSs in which the apices are close to the entry points of the temporal and medial SPCA bundles into the eye. The more rectangular nature of choroidal ischaemia affecting the vertical meridional choroidal is less well known but was recognised by Amalric ${ }^{16,21}$ and corresponds to the area supplied by recurrent choroidal branches from the superior and inferior parts of the 'circle' of Haller and Zinn, which is a more linear origin.

Fryczskowski ${ }^{41}$ noted the triangular openings of the choroidal arterioles into the submacular choriocapillaris from which functional specialisation was inferred. These were found routinely at the posterior pole and helped to identify lobular pattern; their morphology reflects the right angled entry of the choroidal arterioles into the choriocapillaris and functional inferences cannot be made. The dense packing of the choriocapillaris at the posterior pole in $\operatorname{man}^{2,5,9,40}$ and monkey $y^{46-49}$ has been well recognised by several authors using different methods of examination. The choriocapillaries have wide diametered flattened capillaris providing a large surface area for metabolic exchange with the pigment epithelium. The retinal surface of the choroidal capillaris is further adapted anatomically for unimpeded metabolic exchange by location of their endothelial nuclei on the sclerad surface. This feature (of endothelial cells in the capillary wall away from Bruch's membrane) was noted by $\mathrm{Hogan}^{4}$ from microscopic examination of the choroid but is more readily observable from rigid methacrylate casts.

Vascular casting supports concepts, based on clinical and experimental evidence, that the choroidal vasculature has a distinct segmental arrangement, both at the level of the larger vessels and at the level of the smaller vessels (choroidal arterioles and choriocapillary lobules) and potential for acute choroidal ischaemia. The triangular shaped infarcts of acute choroidal ischaemia correspond to larger vessel occlusion and focal or geographic infarcts corresponding to smaller vessel and choriocapillary occlusion. However, the choroidal circulation is not truly endarterial since there are potential collaterals from inter-arteriolar and inter-venular anastomoses and recovery of acute choroidal ischaemia may be rapid and spontaneous. Vascular casting also demonstrates the anatomical adaptation of the capillaries for metabolic exchange with the retinal pigment epithelium, particularly at the posterior pole. It is a useful tool to demonstrate the functional anatomy of the choroidal circulation, considered in conjunction with dynamic and physiological aspects. 
I am grateful to Professor Alan Bird for his helpful advice in the preparation of this manuscript and to $\mathrm{Mr}$ David Spalton for arranging permission to study postmortem specimens.

\section{References}

${ }^{1}$ Zinn IG: Descriptio Anatomica Oculi Humani. first Ed., Gottingen. Abrami Vandenhoeck. 1755: 27-56.

${ }^{2}$ Leber T: Die Circulations und ernahrungsverhaltnisse des Auges. (Graefe-Saemisch Handbuck der Gesantum Augenheilkunde). Leipzig: Engelman, 1903.

${ }^{3}$ Hayreh SS: The ophthalmic artery III. Br J Ophthalmol 1962, 46: 212-47.

${ }^{4}$ Hogan MJ: Ultrastructure of the choroid its role in the pathogenesis of chorioretinal disease. Trans Pac Coast Oto-Ophthal Soc 1961, 42: 61-87.

${ }^{5}$ Weiter JJ and Ernest JT: Anatomy of the choroidal vasculature. Am J Opthalmol 1974, 78: 583-90.

${ }^{6}$ Friedman E, Smith TR, Kuwabara T: Senile choroidal vascular patterns and drusen. Arch Ophthalmol 1963, 69: 220-30.

${ }^{7}$ Klien BA: Regional and aging characteristics of the normal choriocapillaris in flat preparations. $A m \mathrm{~J}$ Ophthalmol 1966, 80, 1191-7.

${ }^{8}$ Krey HF: Segmental vascular patterns of the choriocapillaris. Am J Ophthalmol 1975, 80: 198-202.

${ }^{9}$ Torczynski E and Tso MOM: The architecture of the choriocapillaris at the posterior pole. Am J Ophthalmol 1976, 81: 428-40.

${ }^{10}$ Ashton N: Observations on the choroidal circulation. Br J Ophthalmol 1952, 36: 465-81.

${ }^{11}$ Wybar KC: A study of the choroidal circulation of the eye in man. J Anat (London) 1954, 88: 94-8.

${ }^{12}$ Wybar KC: Vascular anatomy of the choroid in relation to selective localisation of ocular disease. Br J Ophthalmol 1954, 38: 513-27.

${ }^{13}$ Ring HG and Fujino T: Observations on the anatomy and pathology of the choroidal vasculature. Arch Ophthalmol 1967, 78: 431-44.

${ }^{14}$ Coats G: Diseases of the choroid. I. Posterior scleritis and infarction of the posterior ciliary arteries. Trans Ophthalmol Soc UK 1907, 27: 135-49.

${ }^{15}$ Hepburn ML: Inflammatory and vascular diseases of the choroid. Trans Ophthalmol Soc UK 1912, 32: 361-86.

${ }^{16}$ Amalric P: Le territoire chorio-retineien de l'artere ciliaire longue posterieure. Etude clinique. Bull Soc Ophthalmol Fr 1963, 63: 342-51.

${ }^{17}$ Amalric P: L'examen cliniques des arteres ciliaires courtes posterieure. Bull Soc Ophtal Fr 1968, 68: $562-67$.

${ }^{18}$ Van Buskirk EM, Lessell S, Friedman E: Pigmentary epitheliopathy and erythema nodosum. Arch Ophthalmol 1971, 85: 369-72.

${ }^{19}$ Foulds WS, Lee WR, Taylor WOG: Clinical and pathological aspects of choroidal ischaemia. Trans Ophthalmol Soc UK 1971, 91: 323-41.

${ }^{20}$ Bird AC and Hamilton AM: Placoid pigment epitheliopathy. Presenting with bilateral serous retinal detachments. Br J Ophthalmol 1972, 56: 881.

${ }^{21}$ Amalric P: Choroidal vessel occlusive syndromes- clinical aspects. Tr Am Acad Ophthalmol and Otolaryngol, 1973, 77: 291-9.

${ }^{22}$ Uyama M, Koshhibu A, Itotagawa S, Ohkuma $\mathrm{H}$, Uragachi K, Miki K: Pathology of choroidal circulatory disturbance. Part 4 . Chorioretinopathy in choroidal circulatory disorders, clinical study. Acta Soc Ophthalmol Jpn 1980, 84: 1947-5.

${ }^{23}$ Coscas G, Gaudric A, Dhermy P, Vernant JP, Cordonnier C: Obstruction choriocapillaire au cours de la maladie de Moschowitz. J Fr Ophthalmol 1981, 4: 101-11.

${ }^{24}$ Gaudric A: Les occlusions vasculaires choroidiennes aigues. Bull Soc Ophthalmol (Fr) 1981 Numcro special 67-133.

${ }^{25}$ Gaudric A, Binachi M, Coscas G: Occlusion choriocapillaire aigue et taches d'Elschnig au cours d'une toxemie gravidique. J Fr Ophthalmol 1981, 4: 223-9.

${ }^{26}$ Gaudric A, Coscas G, Bird AC: Choroidal ischacmia. Am J Ophthalmol 1982, 94: 489-98.

${ }^{27}$ Wagenmann A: Experimentalle untersuchungen uber den einfluss der circulation in den netzhaut-und aderhautgefassen auf dic crnahrung des auges, insbesondere der retina, und uber die folgen der sehnervendurchschneidung. Albrecht v. Graefes Arch $f$ Ophthalmol 1890, 36: 1-120.

${ }^{28}$ Nicholls JVV: The effect of section of the posterior ciliary arteries in the rabbit. $\mathrm{Br} J$ Ophthalmol 1938, 22: 672-87.

${ }^{29}$ Dollery CT, Henkind P, Kohner EM, Paterson JW: Effects of raised intraocular pressure on retinal and choroidal circulation. Invest Ophthalmol 1968, 7: 191-8.

${ }^{30}$ Hayreh SS and Baines JAB: Occlusion of the posterior ciliary artery. I. Effects on choroidal circulation. Br J Ophthalmol 1972, 56: 719-35.

${ }^{31}$ Hayreh SS and Baines JAB: Occlusion of the posterior ciliary artery. II. Chorioretinal lesions. $\mathrm{Br} \mathrm{J}$ Ophthalmol 1972, 56: 736-53.

${ }^{32}$ Stern WH and Ernest JT: Microsphere occlusion of the choriocapillaris in rhesus monkey. Am J Ophthalmol 1974, 78: 438-48.

${ }^{33}$ Hayreh SS: Sub-macular choroidal vascular pattern. Experimental fluorescein fundus angiographic studies. Albrecht v. Graefes Arch Klin Exp Ophthalmol 1974, 192: 181-96.

${ }^{34}$ Hayreh SS: Segmental natu:e of the choroidal vasculature. Br J Ophthalmol 1975, 59: 631-48.

${ }^{35}$ Uyama M, Ohkuma H, Itotagawa S, Koshibu A, Uraguchi K, Koichiro M: Pathology of choroidal circulatory disturbances. Part I. Angioarchitecture of the choroid, observations on plastic cast preparations. Acta Soc Ophthalmol Jpn 1980, 84: 1893-909.

${ }^{36}$ Potts AM: Anatomic methods for study of the bulbus oculi. Am J Ophthalmol 1968, 65: 155-63.

${ }^{37}$ Ducournou DH: A new technique for the anatomical study of the choroidal blood vessels. Ophthalmologica 1982, 184: 190-7.

${ }^{38}$ Woodlief NF and Eifrig DE: Initial observations on the microcirculation in man; the choriocapillaris. Ann Ophthalmol 1982, 14: 176-80.

${ }^{39}$ Yoneya S, Tso MOM, Shimizu K: Patterns of the choriocapillaris. A method to study the choroidal vasculature of the enucleated human cyc. Int Ophthalmol 1983, 6: 6-9.

${ }^{40}$ Yoneya S and Tso MOM: Angioarchitecture of the 
human choroid. Arch Ophthalmol 1987, 105: 681-7.

${ }^{41}$ Fryczkowski AW and Sherman MD: Scanning electron microscopy of human ocular vascular casts: The sub-macular choriocapillaris. Acta Anat 1988, 132: 265-69.

${ }^{42}$ Olver JM and McCartney ACE: Orbital and ocular micro-vascular casting in man. Eye (in press).

${ }^{43}$ Itotagawa S: Observation on the choroidal vasculature. III. Recovery of blood flow in choroidal circulation after occlusion of the posterior ciliary arteries. Acta Soc Ophthalmol Jpn 1979, 83: 2132-41.

${ }^{44}$ Uyama M, Itotagawa S, Uragachi K, Ohkuma H, Miki K, Koshibu A: Pathology of choroidal circulatory disturbance. Part II. Deprivation of the choroidal blood flow and its recovery, an experimental study. Acta Soc Ophthalmol Jpn 1980, 84: 1910-23.

${ }^{45}$ Nopanitaya W, Aghajanian JG, Gray LD: An improved plastic mixture for corrosion casting of the gastrointestinal microvascular system. Scanning Electron Microscopy. SEM Inc, AMF O'Hara. Il 60666, USA. 1979, 3: 751-6.
${ }^{46}$ Fahrenbach WH, Bacon DR, Morrison JC, van Buskirk EM: Controlled vascular corrosion casting of the rabbit eye. J Electron Microsc Tech 1988, 10: $15-26$.

${ }^{47}$ Olver JM, Spalton DJ, McCartney ACE: Microvascular study of the retrolaminar optic nerve in man: Its possible relevance in the aetiology of anterior ischaemic optic neuropathy. Eye (in press).

${ }^{48}$ Shimizu K: Segmental nature of the angioarchitecture of the choroid. Acta XIII Concilium Ophthalmologicum, Kyoto 1978. Chapter 4, pp. 215-19. Ed. Shimizu K, Oosturhuis JA. Excerpta Medica Amsterdam Oxford.

${ }^{49}$ Araki M: Observations on the corrosion casts of the choriocapillaries. Acta Soc Ophthalmol Jpn 1976, 80: $315-26$.

${ }^{50}$ Itotagawa S, Fukami K, Doi H: Observations on the plastic cast of the choroidal vasculature. Part I. Vascular characteristics in the sub-macular area. Acta Soc Ophthalmol Jpn 1977, 81: 678-87.

${ }^{51}$ Ujiie K and Hanyuda T: Three-dimensional architecture of the peripheral choroid and the ciliary body. 